\title{
Rebuilding fisheries will add to Asia's problems
}

\section{Overfishing has already caused depletion and conflict. Instead, train people for new jobs.}

Sir - The tsunami that hit south and southeast Asia, taking a horrific toll in human lives, also affected several coastal industries, including tourism, agriculture and shrimp farming, though to what extent is unclear. As noted in your News story "Scientists seek action to fix Asia's ravaged ecosystems" (Nature 433, 94; 2005), the effects in some areas were exacerbated by existing environmental problems stemming from settlement and industry.

The governments of Thailand and Indonesia have announced some estimates of fishing boats lost and highlighted the need for investments to restart the fisheries. However good their intentions, I believe that Western aid agencies, and indeed, the governments of the region would be ill-advised to rebuild the fisheries as they were before the tsunami.

Apart from oceanic fisheries for tuna and other large fish, fisheries in the tsunami-affected region fall into two categories: 'artisanal fisheries', relying on small (5 m or less), owner- or familyoperated craft, some unmotorized; and 'industrial fisheries', using larger vessels, mainly trawlers but also other specialized craft with salaried crews.

Jointly, their fishing activities have radically depleted the nearshore resources, down to depths of $100 \mathrm{~m}$ in places. Governments in the region have tried to encourage the industrial fisheries to operate farther offshore, but with little success, mainly because biological production, in tropical waters, is much higher inshore than offshore. Hence the artisanal and industrial fisheries essentially target the same shrimp and fish stocks, leading to intense competition.

This competition and the ensuing violence, including boat burnings and riots, can be serious enough to prompt governments to take action, such as the 1980 ban on bottom trawlers in western Indonesia. Usually, however, government policies ignore these conflicts. Sometimes they exacerbate conflict by subsidizing the construction and operation of industrial vessels, even in cases where these do not add to the total catch, but reduce that of the artisanal fishers.

International aid has often aggravated this through technological and capital transfers, or donations of surplus vessels.
Meanwhile, failed agricultural and social policies aggravate the situation by driving thousands of landless farmers to coastlines, where they usually fail to emulate the more sustainable ways of 'traditional' fishers.

After the tsunami, the initial push will be to get people back to the jobs they know, and it will be hard to argue otherwise in the midst of the chaos. But rebuilding the fisheries without structural reform will only intensify these trends and conflicts.

The challenge is to rebuild fisheries while directing as much money and energy as possible to generating land-based job opportunities for young fishers. Emphasis should be given to basic education and technical skills: many fishers in south and southeast Asia are illiterate, and this limits their social mobility.

Amending the old adage that teaching people to fish is better than giving them a fish to eat, we should instead be teaching them to repair bikes, sewing machines and water pumps.

\section{Daniel Pauly}

Fisheries Centre, 2259 Lower Mall, University of British Columbia,

Vancouver, British Columbia V6T 1Z4, Canada

\section{Need for a risk-informed} \section{tsunami alert system}

Sir - The tsunami death toll from the earthquake of 26 December 2004 is a tragedy of such dimensions that it creates a tipping point in hazard perception and risk management, with existing procedures being thrown into a new and critical light ("Inadequate warning system left Asia at the mercy of tsunami" Nature 433, 3-6; 2005).

In particular, an urgent review is needed of the process for issuing tsunami warnings. Developed by Earth scientists over four decades, it has insufficient input from risk specialists who understand the difficulties of emergency decision-making under uncertainty.

Tsunamis occur most frequently in the Pacific Ocean, so existing monitoring and warning systems have been developed for those conditions. Because earthquakes that could lead to a tsunami happen about once a year on average, concern over the economic cost of false alarms means that detecting a very large earthquake is not enough - additional data from pressure sensors or tide gauges are needed to confirm that a tsunami has indeed been generated.

Outside the Pacific Ocean, it would be impractical to insist on certainty before issuing a warning. Without adequate monitoring of seismic activity and sea conditions, such an approach may be ineffective. Furthermore, in developing nations with high population density, the cost-benefit balance between human safety and financial loss is tilted more heavily towards avoidance of mass casualties than in affluent Hawaii or Oregon.

An alternative approach is to establish evidence-based criteria for raising different levels of tsunami alert. This would reduce the chance of complete alert failure, at a cost of some additional false alerts.

An analogy might be made with gale warnings, whereby the possibility of a severe storm is sufficient for seafarers to be alerted some hours in advance, but not forcibly grounded.

A risk-informed warning system, based on global online tsunami databases (see www.ngdc.noaa.gov/seg/hazard/tsu.shtml and tsun.sscc.ru/tsulab/On_line_Cat.htm), and implemented via the Bayesian Belief Network formalism, could help decisionmakers incorporate the intrinsic uncertainties in tsunami forecasting.

Belief Networks are probabilistic inference graphs providing a logical basis for reasoning under uncertainty, and aid decision-making by accounting jointly for uncertainties associated with accumulated experience (including expert judgement) and with processed statistical data. Such a scheme would provide a rational basis for tsunami alerts, and allow for a new lowalert level, akin to a gale warning, that would advise against sea and beach excursions during times of heightened risk after a major earthquake.

For coastal authorities, a low-level false alarm every few years would be a small price to pay for avoiding a catastrophe. Indeed, such warnings may prove costeffective, if the return of tourism requires reassurance. And as with fire drills, the occasional alert would serve as a useful reminder to the local community of a latent threat.

Gordon Woo*, Willy Aspinall $\dagger$

${ }^{\star}$ Risk Management Solutions Ltd,

Peninsular House, 30 Monument Street,

London EC3R 8HB, UK

$\dagger$ Department of Earth Sciences,

Bristol University,

Wills Memorial Building, Queens Road,

Bristol BS8 1RJ, UK

\section{correspondence}

Contributions to Correspondence may be submitted to corres@nature.com. They should be no longer than 500 words, and ideally shorter. Published contributions are edited. 